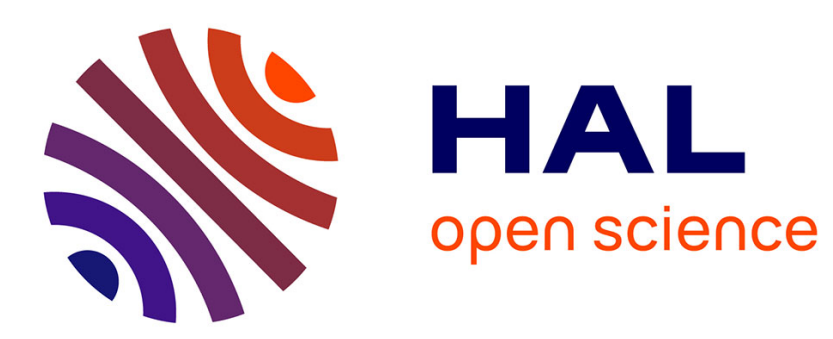

\title{
Physical models of off-road vehicles moving on loose soils
} Annie Luciani, Benoît Chanclou

\section{To cite this version:}

Annie Luciani, Benoît Chanclou. Physical models of off-road vehicles moving on loose soils. International Conference on Robots and Systems 1997, 1997, Grenoble, France. pp.2. hal-00910593

\section{HAL Id: hal-00910593 \\ https://hal.science/hal-00910593}

Submitted on 22 May 2014

HAL is a multi-disciplinary open access archive for the deposit and dissemination of scientific research documents, whether they are published or not. The documents may come from teaching and research institutions in France or abroad, or from public or private research centers.
L'archive ouverte pluridisciplinaire HAL, est destinée au dépôt et à la diffusion de documents scientifiques de niveau recherche, publiés ou non, émanant des établissements d'enseignement et de recherche français ou étrangers, des laboratoires publics ou privés. 


\title{
Physical Models of Off-Road Vehicles Moving on Loose Soils
}

\author{
Annie Luciani and Benoît Chanclou \\ Annie.Luciani@imag.fr \\ ACROE, 46, Avenue Félix Viallet - 38031 Grenoble Cedex, France
}

\begin{abstract}
This video illustrates physically-based particle simulations of various off-road vehicles moving on deformable soils, leaving tyre traces, spinning, skidding and even sinking.
\end{abstract}

Key Words - Physical Modeling, Dynamic Simulation, Off-Road Vehicle, Loose Soil.

\section{Introduction}

Manufactured soils have simple dynamical behaviour, such as quite-rigid behaviours. Then, we can model the system soil - vehicle as an open- looped system taking into account only the action of the soil onto the vehicle. At the opposite, natural environnements present more complex dynamical behaviors : rolling stones, non neglictible deformations, compressions, avalanches, collapses... The geometry of the terrain can highly modify by the vehicle itself during its displacements. And simultaneously, the behavior of the vehicle becomes also more complex : sliding, skidding, slipping ... The modelling of this situation requires the use of closed-loop systems, in which the soil physically acts on the vehicle, modifying its motion, and at the same time, the vehicle physically acts on the soil, causing deformations and transformations.

Deformable soils, such as loose soils cannot be modelled by solid physics and they require the use of punctual mass decomposition and mass-mass interactions.

These are the basis of the modellor-simulator called CORDIS - ANIMA we used, in which every kind of physical object is modelled by a set of punctual masses in physical interaction [2] [3]. The interactions can be linear elasticities and linear viscosities as well as non linear elastic bumper, cohesion interaction, dry friction, and plastic interaction, used in these works.

\section{Deformable Soil Models}

With this physically-based particle modeler, we have developped physical models of rigid soils with dynamical dry friction, and deformable soils composed of rigid parts such as a substratum with rigid stones able to roll on it, under the action of the vehicle [1] [4] [5].
In [7], we have been interested on the modelling of loose soils such as sand layers. The first stage has been to model the sand itself and more generally granular material in different conditions ; dry sand, moist muds. The model is composed of a set of punctual masses, all linked by visco-elastic buffer interactions and poured on a rugged medium. As it can be see on the video, with this model, we obtained the major phenomena which caracterize the dynamical behaviour of granular materials : different kinds of piling, surfacic avalanches, collapses, arching and so on.

To model loose soils, the second stage, is to adapt this general model of granular material to the specificity of soils. Instead of the lot of phenomena occuring in granular materials such as large avalanches and collapses, what we need in soil modelling is mainly compression, shear and plastic deformations. Then, we designed, from the first model of granular materials, an optimized model for the soil, which has a contant layer-based topology [9] [10].

\section{Modeling Plasticity}

Then, plasticity must be modelled in another way : Not as an emergent phenomena due to the sum of microscopic collisions but as a complex interaction component producing directly plasticity. The so called plastic interaction is elastic for small deformations; after a threshold, called "plastic threshold", it remains elastic but with another rest deformation, and so an ...

Then, a loose soil can be modelled by a set of masses linked by three plastic interactions : a vertical interaction to model the compression resistance; an horizontal one to model the shear; a mass-mass interaction to model the cohesion forces in the soil surface. By adjusting the rest position of these masses, we draw the geometrical profile of the rigid substratum [9] [10]. Because plastic interaction has successive irreversible thresholds, we model irreversible complex compressions and shears with successive stages of compression or shear, according to the history of the system. The video illustrates these phenomena.

\section{Physically-Based Models of Vehicles}

Our vehicles must move on every kind of soils: rigid, rigid and mobile, but also deformable and loose soils. We 
cannot use other discretisation elements than punctual masses. We have used also the CORDIS - ANIMA modelor-simulator to model every kind of vehicles, having rigid parts such as chassis or deformable parts, such as wheels with tires [6].

To be always physically consistant with the physical representation system used for soils and chassis, we have created an elementary Cordis-Anima actuator which satisfies to physical action - reaction principle. With this physically consistant actuator, we motorized several part of the vehicle : the wheels, the automatic steering and the peristaltic motion of the chassis.

\section{Simulation Results and Video Contents}

The video shows a set of dynamically - based simulations of different kinds of vehicles, with different kinds of motorization, moving on loose soils.

It contains successively :

- Vehicles moving on rigid soils [1]:

The rovers have no internal motors. But there is a dry friction between the wheels and the soil.

- Vehicles moving on mobile soils [1]:

Rocks are mobile and there is dry friction between wheels and pebbles and pebbles and substratum. The video illustatres the action from the rover to the rocks and the action from the rocks to the rover.

- Experiments on the simulation of granular material [7]: Thanks to the dry friction between each mass and the ground for causing the piling, the avalanches and the internal collapses.

- A rocky-type rover moving on a loose soil [6] [9] [10]:

The interactions between the rover and the soil are visible. The rover marks the soil and the soil modifies the motion of the rover. The video illustrates the progression of the compression after the crossing of the first wheel, the second and the third and the simultaneous deformations of the soil and of the wheel.

- A 2D-wheels motorized rover :

The rover skids when it tries to climb the slope. But the soil is a loose soil, so the wheels pack the soil and the grip is recovered.

- A rover with two tracked bogies [6] [9] [10] :

With this rover, we can see the behavior of a rocky type rover. The axis of the front bogie can be moved back or forth. So it is possible to study the influence of mass distribution on the rover's capacities.

- A rover with dynamically controlled peristaltic motion :

The video shows the influence of the peristaltic motion on the crossing over of the vehicle moving on plastic natural profiled terrain [6] [9] [10].

- 3D simulation with rendering [6] [9] [10] :

To perform such simulations, we have created soil models. Then, path planning was performed. The path is obtained by physical modeling. Once the control points' position are obtained, the simulation of the rover can be performes. The first simulation shows a rover with its steering which marks a loose soil. The second simulation shows a rover moving on this kind of soil with rigid pebbles bore on it. On the third simulation, the rover cannot cross over the slope. The wheels are sliding and the vehicle stops.

- Force feed back real time driving [8]:

The last sequence shows a real time simulation. This simulation is done with a two dimensionnal vehicle control by a force feedback gestural interface. This interface reads positions and return forces with a $1 \mathrm{KHz}$ sampli,g rate. This rate allows to realistically feel hard collisions and vehicle behavior.

\section{Bibliography}

[1] S. Jimenez, A. Luciani, C. Laugier, "Simulating Physical Interactions between an Articulated mobile vehicle and a terrain ", 4e Symposium International sur l'Offshore et la robotique, Marseille décembre 91, reprint in Journal on Robotics and Autonomous Systems, Elsevier Sc Pub 92

[2] A. Luciani, S. Jimenez, C. Cadoz, JL. Florens, O. Raoult, "An unified View of Multitude Behaviour, flexibility, plasticity and fractures balls, bubbles and agglomerates ", Proc. of the IFIP WG 5.10, in Modeling in Computer Graphics, T.L. Kunii Ed., Springer Verlag,1991

[3] A. Luciani, S. Jimenez, JL. Florens, C. Cadoz, O. Raoult, "Computational physics : a modeler simulator for animated physical objects", Proceedings of the European Computer Graphics Conference and Exhibition. Vienna, Austria, Septembre 91, Editeur Elsevier

[4] S. Jimenez, A. Luciani, C. Laugier, "Teleprogramming the motions of a planetary robot using physical models and dynamic simulation tools", IROS' 92, IEEE Ed., July 92

[5] S. Jimenez, A. Luciani, "Animation of Interacting Objects with Collisions and Prolonged Contacts", Proc. of the IFIP WG 5.10, in Modeling in Computer Graphics - B. Falcidieno \& T.L. Kunii Ed., Springer Verlag Pub. - 1993

[6] B. Chanclou, A. Luciani - "Physical models and dynamic simulation of planetary motor vehicles with a great number of degrees of freedom"- Proc of IAS 4 Conf. - IOS Press - 1995 - pp 465-472

[7] A. Luciani, A. Habibi, E. Manzotti- "A Multi-scale Physical Models of Granular Materials", Proc. of Graphics Interface '95, 16-19 May 1995, Quebec City, Canada pp136-146

[8] C. Uhl, JL. Florens, A. Luciani, C. Cadoz - "Hardware Architecture of a Real Time Simulator for the CordisAnima System :Physical Models, Images, Gestures and Sounds" - Proc. of Computer Graphics International '95 Leeds (UK), 25-30 June 1995 - , Academic Press. - RA Ernshaw \& JA Vince Ed. - pp 421-436

[9] B. Chanclou, A. Luciani, A. Habibi, "Physical models of loose soils marked by a moving object" - Proc. of Computer Animation 96 - IEEE computer Soc Press 1996 - pp36-46

[10] B. Chanclou, A. Luciani, "Physical modeling and Dynamic Simulation of Off-Road Vehicles and Natural Environments" - Proc. of the 1996 IEEE/RSJ International Conference on Intelligent Robots and Systems, IROS'96, IEEE ed, 1996, pp 505-512 